\title{
Long-Lasting Neural and Behavioral Effects of Iron Deficiency in Infancy
}

\author{
Betsy Lozoff, John Beard, James Connor, Barbara Felt, Michael Georgieff, and \\ Timothy Schallert
}

Infants are at high risk for iron deficiency and irondeficiency anemia. This review summarizes evidence of long-term effects of iron deficiency in infancy. Follow-up studies from preschool age to adolescence report poorer cognitive, motor, and social-emotional function, as well as persisting neurophysiologic differences. Research in animal models points to mechanisms for such long-lasting effects. Potential mechanisms relate to effects of iron deficiency during brain development on neurometabolism, myelination, and neurotransmitter function.

Key words: behavior, brain development, infants, iron deficiency, monkeys, rodents

(c) 2006 International Life Sciences Institute

doi: 10.1301/nr.2006.may.S34-S43

\section{INTRODUCTION}

Iron deficiency is the most common single nutrient disorder in the world, ${ }^{1}$ and infants are at particular risk due to their rapid growth and limited dietary sources of iron. ${ }^{2}$ Iron is involved in many central nervous system processes that could affect infant behavior and development. ${ }^{3}$ Our focus here is on long-lasting effects and

Drs. Lozoff and Felt are with the Center for Human Growth and Development and the Department of Pediatrics and Communicable Diseases, University of Michigan, Ann Arbor, Michigan, USA; Dr. Beard is with the Department of Nutritional Sciences, The Pennsylvania State University, University Park, Pennsylvania, USA; Dr. Connor is with the Department of Neurosurgery, Hershey Medical Center, The Pennsylvania State University, Hershey, Pennsylvania; Dr. Georgieff is with the Department of Neonatology, University of Minnesota, Minneapolis, Minnesota, USA; and Dr. Schallert is with the Department of Psychology, University of Texas, Austin, Texas, USA.

Please address all correspondence to: Dr. Betsy Lozoff, Center for Human Growth and Development, $300 \mathrm{~N}$. Ingalls, University of Michigan, Ann Arbor, MI 48109; Phone: 734-764-2443; Fax: 734-936-9288; E-mail: blozoff@umich.edu. possible explanatory mechanisms, drawing on studies in the human infant and the developing rodent.

\section{HUMAN INFANT STUDIES}

\section{Alterations During or Soon After the Period of Iron Deficiency}

Differences in mental, motor, social/emotional, and neurophysiologic functioning observed while infants are iron deficient will be briefly summarized to lay the groundwork for considering long-term effects and explanatory mechanisms. Considerable research on iron deficiency in the human infant has involved otherwise well-nourished, healthy 6- to 24-month-old babies born at term with normal birth weights and without perinatal problems. At least 27 such studies (of varying quality) have been conducted in countries around the world. Case-controlled studies and preventive trials published before 2001 have been summarized in an excellent review by Grantham-McGregor and Ani, ${ }^{4}$ and most are not individually cited here. Studies involving infants at risk for stunting have often been controlled trials of supplemental iron in developing countries, generally combined with other micronutrients. ${ }^{5-12}$ They will not be discussed, since there are no published long-term follow-up studies as yet. This body of research is also summarized in recent reviews. ${ }^{13,14}$

In almost all case-control studies comparing otherwise healthy full-term infants with iron-deficiency anemia to infants with better iron status, their mental development test scores averaged 6 to 15 points lower. Of the few available preventive trials, our study in Chile was the only one to show the effects of iron supplementation on mental functioning. ${ }^{15}$ Infants who did not receive supplemental iron had longer looking times on a visual recognition memory task, suggesting poorer high-speed information processing on a measure that predicts later IQ. Among case-control studies that included an assessment of motor development, most found that infants with iron-deficiency anemia received lower motor test scores, 
averaging 6 to 17 points lower. A new study with 9-month-old infants in Detroit shows linear effects of iron status on gross motor development and motor coordination/sequencing. ${ }^{16}$ A population study in the UK found that hemoglobin $(\mathrm{Hb})$ levels under $95 \mathrm{~g} / \mathrm{L}$ at 8 months predicted poorer locomotor development at 18 months. ${ }^{17}$ Among five preventive trials with well-nourished term infants, three showed motor benefits of iron supplementation. ${ }^{15,18,19}$

Virtually every case-controlled study that examined social-emotional behavior found differences in iron-deficient anemic infants (e.g., more wary, hesitant, solemn, unhappy, kept closer to their mothers). Two of three randomized trials to prevent iron deficiency that assessed this domain reported social-emotional differences as well. Infants who did not receive prophylactic iron received poorer scores in the personal/social domain in one trial. ${ }^{20}$ In our Chile study, more of the group that did not receive supplemental iron showed no social interaction, no positive affect, no social referencing, an inability to be soothed by words or objects, and a lack of protest when toys were taken away. ${ }^{15}$ One preventive trial did not find social-emotional effects. ${ }^{18}$ In the few studies (case-controlled) to include neurophysiologic measures, differences have been observed in the speed of neural transmission in the auditory system, ${ }^{21,22}$ rapid eye movement density in active sleep, ${ }^{23}$ recognition memory with event-related potentials (ERP), ${ }^{24}$ and EEG frontal asymmetry. ${ }^{25}$ One study did not find altered auditory system neurotransmission. ${ }^{26}$ Differences between home and laboratory results in spontaneous motor activity in the Chile study suggest that iron-deficient anemic infants respond differently to context-with a reduction in motor activity associated with the stress or unfamiliarity of the laboratory. ${ }^{27,28}$

Many of the case-controlled studies have included assessments before and immediately after iron therapy. Most studies report that differences in behavior and development persist in the majority of iron-deficient anemic infants even after a full course of iron treatment (2-6 months, depending on the study). ${ }^{4,13}$ However, three studies reported improvements, sometimes dramatic, in mental and/or motor test scores after iron therapy. ${ }^{29-31}$

Perinatal (i.e., late fetal and neonatal) iron deficiency has received little attention, due in large part to previous thinking that infants are protected from maternal iron deficiency unless the mother is markedly anemic. $^{32}$ Two studies related perinatal iron deficiency to newborn temperament-like behaviors. One reported higher levels of irritability in infants whose mothers were iron deficient. ${ }^{33}$ In the other, ${ }^{34}$ lower levels of neonatal $\mathrm{Hb}$ and serum iron (and ferritin to a lesser degree) were correlated with higher levels of negative emotionality and lower levels of alertness and soothability. A small randomized, controlled trial involving breast-fed infants in Canada showed a benefit of early (between 1 and 6 months of age) iron supplementation on motor development and visual acuity at 12 months. ${ }^{19}$

Some groups of newborns are at risk for iron deficiency, even without maternal iron deficiency. These include infants of diabetic mothers, growth-restricted newborns, and preterm infants. ${ }^{35}$ In the only developmental study of iron-deficient premature infants, a number of reflexes were less mature in those with iron deficiency anemia. ${ }^{36}$ Full-term newborn infants of diabetic mothers had poorer recognition memory as measured by ERP and/or behavioral tests as newborns and throughout the first 12 months. ${ }^{37-39}$ Effects were most prominent in those infants with low cord ferritin concentrations. $^{40}$

\section{Long-Lasting Effects Beyond Infancy}

\section{Global Outcomes}

There are several studies, again of varying quality, of the long-term effects of early postnatal iron deficiency. These studies, most of which have been conducted at late preschool or early school age, followed children who had anemia (presumably due to iron deficiency), iron-deficiency anemia, or other indications of chronic severe iron deficiency in infancy. Because iron deficiency is likely to occur under disadvantaged family circumstances, ${ }^{41}$ control for background factors is an important consideration in interpreting follow-up results and will be specified in reviewing each study.

There are at least six follow-up studies at late preschool age. One included a relatively large group of Israeli children who had $\mathrm{Hb}$ determinations at 9 months and assessed their development at 2, 3, and 5 years $(\mathrm{N}=$ 873,388 , and 239 , respectively). ${ }^{42}$ Although $\mathrm{Hb}$ was the only measure of iron status, iron deficiency was widespread and anemia was presumed to be due to iron deficiency. After statistical control for the influence of basic background characteristics, $\mathrm{Hb}$ at 9 months correlated with IQ at 5 years (trends at 2 and 3 years were suggestive). At 5 years, each $10 \mathrm{~g} / \mathrm{L}$ increment in $\mathrm{Hb}$ was associated with a 1.75 point-higher IQ score. ${ }^{42}$ Another study of a primarily immigrant population in France followed children from 10 months to 4 years of age $(\mathrm{N}=$ 147). ${ }^{43}$ Iron deficiency anemia at 10 months did not correlate with later development, but the iron measures utilized can be difficult to interpret in infants less than a year of age. However, mean cell hemoglobin concentration at 2 years, controlling for a limited set of background factors, was positively associated with overall developmental, motor, and social quotients at 2 years and 
with overall developmental quotient at 4 years. Yet another preschool follow-up was conducted in Yugoslavia in conjunction with a study on elevated lead levels. Children were followed from birth to 4 years, with hematology at $6,12,18$, and 24 months, ${ }^{44}$ and 3 and 4 years $^{45}(\mathrm{~N}=392$ in infancy, 388 at 3 years, and 332 at 4 years). $\mathrm{Hb}$ at 6 months predicted IQ at 4 years, as did $\mathrm{Hb}$ at 36 months. All findings controlled for a comprehensive set of background variables that included Home Observation for Measurement of the Environment (HOME) score, maternal IQ, and lead levels, as well as commonly considered factors such as birth weight, sex, parental education, and occupation.

Two preschool follow-up studies were similar in their test batteries, comprehensive background data, and multiple measures of iron status. Our study in Costa Rica assessed 5-year-old children who varied in iron status as infants. ${ }^{46}$ All those with iron deficiency were treated with a full course of iron in infancy, and none had iron deficiency anemia after treatment or at subsequent follow-ups. Of the original sample of 191 infants, 163 $(85 \%)$ were tested at 5 years. After controlling for background variables including maternal IQ, HOME, and infant lead level, the group with moderate irondeficiency anemia $(n=30)$ showed lower test scores on performance IQ; quantitative, preschool cluster, perceptual speed, and visual matching subtests of the Woodcock Johnson; visual motor integration; and gross and fine motor performance. In addition, children with $\mathrm{Hb}$ levels over $100 \mathrm{~g} / \mathrm{L}$ in infancy whose biochemical indicators of iron deficiency had not been fully corrected with iron therapy $(n=18)$ had a similarly poor performance. These groups were combined to form a chronic, severely iron-deficient group in subsequent analyses. In a structured mother-child interaction task at 5 years, they displayed lower levels of physical activity, positive affect, verbalization, and reciprocal interaction. ${ }^{47}$ The study by De Andraca et al. ${ }^{48}$ assessed 77 Chilean 5- to 6-year-old children, 41 with iron-deficiency anemia in infancy and 29 who had been non-anemic. The former iron-deficient anemic group tested lower in IQ, psychoeducational abilities, visual motor integration, and language abilities. They were also more neurologically immature, as assessed by a highly skilled neurologist. Controlling for neurologic maturity and background factors, differences in psycho-educational, language, and fine motor abilities were still statistically significant. ${ }^{48}$

The above preschool follow-up studies involved infants who were identified as having iron deficiency in the infant/toddler period, presumably as a function of low dietary intake, rapid growth, and perhaps lower iron stores at birth. Only one study has related a direct measure of iron status at birth (cord ferritin concentration) to development years later. ${ }^{49}$ In this sample of 278
US children, those with cord ferritin concentrations in the lowest quartile received lower scores for language ability, fine-motor skills, and tractability at 5 years.

There are at least four reports of outcome in schoolaged children. The very earliest study, published only in abstract form, ${ }^{50}$ assessed 7-year-old US children who, as full-term infants, had received intramuscular iron and had not been anemic in infancy $(n=29)$ or who developed anemia ( $\mathrm{Hb}=61-95 \mathrm{~g} / \mathrm{L})$ between 6 and 18 months $(n=32)$. The formerly anemic children were more likely to show soft neurologic signs, such as clumsiness, and be more inattentive and hyperactive, and their IQs averaged 6 points lower. In the Israeli study described above, a subset was reassessed in 2 nd grade. ${ }^{51}$ Teacher ratings of behavior were obtained for 20 children who had been anemic at 9 months $(\mathrm{Hb}<105 \mathrm{~g} / \mathrm{L})$ and 56 who had been non-anemic $(\mathrm{Hb}>115 \mathrm{~g} / \mathrm{L})$. Controlling for a comprehensive set of background characteristics, including maternal IQ, HOME score, and lead levels, teachers rated the formerly anemic group as significantly lower in learning and positive task orientation. $^{31}$

Another important study of long-term outcome was conducted statewide in Florida. ${ }^{52}$ Anemia in infancy, based on Hb screening in the Women, Infant, and Children (WIC) program, was associated with special education placement at 10 years, based on the criteria used by the Florida Department of Education for mild or moderate mental retardation. Although this study was limited in that $\mathrm{Hb}$ was the sole measure of iron status, it is exceptional in relating anemia in infancy (presumably due to iron deficiency) to increased risk of mental retardation or special education placement among schoolaged children in an entire population $(\mathrm{N}=3771)$. After controlling for a basic set of background characteristics, the risk of placement for special education increased by 1.28 for each unit lower $\mathrm{Hb}$ at entry into the WIC program.

There is only one follow-up study past 10 years of age. In early adolescence (11-14 years), we reevaluated 167 of the children in the Costa Rica cohort described above $\left(87 \%\right.$ of the original infant sample). ${ }^{53}$ Again controlling for a comprehensive set of background factors, the 48 children who had been treated for severe, chronic iron deficiency in infancy still tested lower in arithmetic and writing achievement and motor function compared with 114 children with good iron status in infancy before and/or after treatment. The proportion that had repeated a grade or been referred for special education or tutoring was 2 to 3 times higher. Affective and social/emotional differences were still observed. The parents and teachers of formerly iron-deficient children rated their behavior as more problematic in several areas, agreeing in increased concerns about anxiety/depression, 
social problems, and attention problems. Growth curve analyses (hierarchical linear modeling) controlling for a comprehensive set of background factors showed no catch-up in motor scores through 11 to 14 years (last time of assessment $)^{54}$ and a widening gap for mental scores through 19 years of age. ${ }^{55,56}$ These patterns were observed regardless of whether scores in infancy had been average or low. The widening gap in mental scores was particularly marked for children from more disadvantaged families.

\section{Neurocognitive and Neurophysiologic Outcomes}

Global tests give little indication about the specific processes that might be affected by iron deficiency in infancy. To provide information on neurocognitive and neurophysiologic outcomes, we have included such measures in our follow-up studies in Costa Rica and Chile. Both of these longitudinal studies now use a similar brain-behavior framework. In both Chile and Costa Rica, children with iron deficiency anemia or some other indication of chronic, severe iron deficiency in infancy had poorer performance on tests of some specific cognitive functions. For the Costa Rica sample at 11 to 14 years, poorer performance was observed for tachistoscopic threshold, spatial memory, and selective attention. ${ }^{53}$ At 5 and 10 years in the Chile follow-up and 19 years in the Costa Rica follow-up, formerly iron-deficient children did worse on executive function tasks, particularly ones that require inhibition and planning. ${ }^{57,58}$

In the Chile study, we evaluated the children at 4 years using auditory brainstem response (ABR) and visual evoked potentials (VEP). ${ }^{59}$ The formerly irondeficient anemic group $(n=41)$ showed longer ABR and VEP latencies compared with children who had been non-anemic in infancy $(n=43)$. The magnitude of effects was large: 1 to $1.2 \mathrm{SD}$. Polysomnographic recordings were obtained during an overnight sleep study for 27 formerly iron-deficient anemic children and 28 children who had been non-anemic in infancy. There were many differences in measures of the sleep/ wake cycle, including REM latency, duration of REM episodes and their pattern through the night, the duration of slow-wave sleep episodes early in the night, both the isolated REMS and non-isolated REMS indices, and inter-REM intervals. ${ }^{60} \mathrm{We}$ also assessed spontaneous motor activity over a 48-hour period using an actigraph. The main finding was an overall increase in intra-individual variability in formerly iron-deficient anemic children, especially for the duration of different states during both day and night. ${ }^{61}$ The overnight sleep studies and the actigraph recordings indicate that iron-deficiency anemia can alter key components of the internal temporal order within the 24-hour cycle. The ABR and VEP findings indicate long-lasting alterations in neurotransmission in two sensory systems that are essential for learning from the physical and social environment.

Thus, studies from countries around the world have yielded generally consistent results regarding long-term outcome. Children who had iron-deficiency anemia, chronic severe iron deficiency, or anemia presumably due to iron deficiency in infancy continue to perform less well then peers who had good iron status in infancy. They have done worse on tests of overall mental, motor, and social/emotional functioning and on specific neurocognitive tests at preschool, school age, and adolescence. Neurophysiologic differences have been observed through the preschool period, and the 10-year follow-up of the Chile sample suggests that differences still persist. Iron deficiency typically occurs in disadvantaged environments, but the findings from several follow-up studies have been statistically significant after controlling for background factors in a wide variety of different settings. Nonetheless, the confluence of iron deficiency with a disadvantaged environment means that causal inferences cannot be made with confidence from casecontrolled, long-term follow-up studies. The consistency of the findings, however, suggests that effects are due to severe, chronic iron deficiency or some closely associated but unidentified factor.

\section{DEVELOPING A RODENT MODEL OF EARLY IRON DEFICIENCY}

Animal studies offer the possibility of studying the effects of iron deficiency that is experimentally induced while controlling for other environmental conditions. They thus play a special role in determining whether iron deficiency causes immediate and long-lasting changes in behavior and development. Animal models also provide direct information about the effects of iron deficiency on the developing central nervous system, and thus help interpret some long-term findings in humans. A burst of basic scientific research has provided important new information. These studies show not only that iron deficiency during gestation and lactation in the rat results in reduced brain iron, but also that the degree varies greatly by brain region. ${ }^{3,62,63}$ This research also points to possible mechanisms for long-lasting effects. The processes under consideration are interconnected, but for the sake of simplicity are summarized under metabolism, myelination, and neurotransmitter function. It is important to point out, however, that new research also shows altered gene and protein profiles. ${ }^{64}$ 


\section{Iron Deficiency and Brain Metabolism during Development}

Periods of peak development and metabolic activity ${ }^{65}$ render some brain regions and processes more vulnerable to deficiencies of substrates that support metabolism. One such substrate, we hypothesize, is iron. The most well-documented effects of iron deficiency are post-translational, resulting from the failure of iron incorporation into protein structures (e.g., cytochromes or iron-sulfur proteins), with subsequent degradation of the protein and loss of function. This perspective leads us to predict that the brain and behavioral consequences of iron deficiency will be a function of timing, severity, and duration ${ }^{66}$ overlaid on the metabolic map of the brain.

Iron deficiency in the human is most prevalent in the late infancy/toddler period. This time period is characterized by peak hippocampal and cortical regional development, as well as myelinogenesis, dendritogenesis, and synaptogenesis in the brain. Studies in the rat point to the vulnerability of the developing hippocampus to early iron deficiency. The neuronal metabolic marker cytochrome $c$ oxidase (CytOx) loss was most marked in the highly metabolic hippocampal areas CA1 and CA3 and in the frontal lobes of the cortex in the iron-deficient rat brain. ${ }^{67}$ Subsequently, nuclear magnetic resonance (NMR) spectroscopy showed that iron deficiencyinduced metabolic changes in the hippocampus at rest were pervasive and long-lasting-all the way through puberty. ${ }^{68}$ Iron deficiency also resulted in altered dendritic structure - a highly energy-dependent process - in pyramidal cells in hippocampal area CA1 during midlactation and in young adulthood, following iron repletion. The results suggest that iron deficiency causes abnormal protein scaffolding for microtubule extension and retraction in brain regions involved in recognition memory processing. ${ }^{69}$ Thus, there appears to be a high rate of local iron regulation for the processes of dendritic extension and remodeling during synaptogenesis, which underlie synaptic plasticity. ${ }^{70}$ It remains to be determined whether the iron deficiency-mediated metabolic and structural changes seen in hippocampus and cortex apply to other brain regions as well. Nonetheless, it is reasonable to postulate that deficits in hippocampus and cortex underlie the deficits in spatial learning observed in rats with iron deficiency in infancy (see below).

\section{Iron Deficiency during Development and Myelination}

In the developing rat, iron deficiency has direct effects on myelin, including a decrease in myelin lipids and proteins. ${ }^{71-75}$ Again, the effects appear to be longlasting. ${ }^{76}$ Rats that had been developmentally iron deficient still manifested myelin deficits at 6 months (adult- hood in the rat). In addition to a general decrease in myelin content, there were also differential effects on individual myelin proteins and phospholipids that are involved in compaction of myelin, as well as other functions. These persisting myelin deficits were observed despite normal concentrations of iron in the myelin fraction and total brain in adulthood. Thus, these data indicate that the timing of iron deficiency and/or aspects of iron delivery during early brain development are more important than ultimately reaching normal concentrations of iron in the brain.

One potential explanation for these long-term myelin effects is that developmental iron deficiency results in a decrease in the number of oligodendrocytes in the adult brain. Accumulating evidence suggests that iron deficiency impacts the proliferation of oligodendrocyte precursor cells and the generation of oligodendrocytes. ${ }^{77}$ Iron deficiency also reduces transferrin and transferrin mRNA, which depend on a normal population of oligodendrocytes in the brain. ${ }^{78,79}$ However, it is not yet known whether fewer oligodendrocytes are available to myelinate axons, or if the metabolism of the oligodendrocytes has been compromised because of a lack of iron availability at crucial periods of development. This is a critical point to be addressed in future studies, because fewer oligodendrocytes might limit the effectiveness of therapeutic interventions.

\section{Iron Deficiency during Development and Neurotransmitter Function}

Neurotransmitter systems are maturing during key periods of high risk for iron deficiency, and iron is essential for a number of enzymes involved in neurotransmitter synthesis. ${ }^{80}$ These include tryptophan hydroxylase (serotonin) and tyrosine hydroxylase (norepinephrine and dopamine). Research over the past 10 years in rodent models has established that: 1) dopaminergic neurons are co-localized with iron throughout the brain; 2) extracellular dopamine and norepinephrine are elevated in brains of iron-deficient rats; 3 ) the density of $\mathrm{D}_{2}$ and $\mathrm{D}_{1}$ receptors and dopamine transporters are altered by dietary iron deficiency; and 4) the degree of alteration in these parameters is tightly connected to the extent of iron loss in the examined brain regions. ${ }^{3}$ Newer studies also demonstrate that the serotonin transporter and norepinephrine transporter densities are altered by dietary iron deficiency, ${ }^{62,63,81,82}$ thus expanding the effect of iron deficiency to all monoamine transporters. The persistence of these alterations into adulthood after iron repletion has recently been examined. ${ }^{63}$ Findings indicate that the $\mathrm{D}_{2} \mathrm{R}$ density remains lower in the substantia nigra, while the serotonin transporter SERT remains lower in lateral and reticular thalamic nuclei and in the 
zona incerta. At the cellular level, iron chelation causes a rapid loss of dopamine transporters from cells, while the turnover of other proteins remains normal. ${ }^{83}$

The effects of early iron deficiency on brain iron and neurotransmitters depend on when they are assessed and on the severity of the iron deficiency. For instance, modest iron deficiency during gestation does not lead to marked changes in rat pup brain iron content until the latter part of lactation. ${ }^{62}$ There are, however, elevations in striatal dopamine transporters, $\mathrm{D}_{2} \mathrm{R}$, and catecholamines that precede measurable changes in regional iron. By weaning, both brain iron and catecholamines are reduced to levels $20 \%$ to $30 \%$ below controls, suggesting that earlier elevations are an "adaptive" response to iron deficiency.

Some of these neurotransmitter alterations may relate to the recently observed effects of early iron deficiency on the neuronal surface protein Thy 1 , which is iron responsive. ${ }^{84}$ In the dietary iron-deficiency model, Thy 1 was decreased in the brains of iron-deficient rats. ${ }^{85}$ Thy1 deficiency may affect the release of neurotransmitters and the synaptic efficacy and could contribute to a variety of abnormal neuron-neuron communications in the iron-deficient rat. The decrease in Thy 1 presumably occurs during the development process, suggesting that adverse effects of iron deficiency have been "wired" into the brain and thus may be difficult to overcome.

\section{Long-Term Behavioral Alterations in the Rat}

Some long-term behavioral alterations in the developmental rat model of early deficiency closely parallel prior experimental studies of specific early dopaminergic insults. Neonatal insults to dopamine neurons result in chronic spatial learning and attentional deficits in adulthood. ${ }^{86-88}$ In a water maze with a submerged platform away from the pool wall, animals with early loss of dopamine terminals persevere in the initial response of searching for an escape route along the walls. This same pattern is observed in rats with developmental iron deficiency and in adult rats with injury to the hippocampus. ${ }^{89}$ The prepotent response interferes with more adaptive behaviors and learning to locate the platform, and is thought to reflect behavioral inflexibility, ${ }^{89}$ which is possibly associated with increased anxiety. ${ }^{63,90}$ Other behavioral tests that tap the capacity to inhibit a prepotent response also show that animals with damage to dopaminergic terminals are impaired in what has been referred to as "executive function." 88

Early dopaminergic insults affect emotional responses as well as cognitive functioning. Rats with neonatal dopamine depletion are hesitant to enter a novel environment or to engage in new tasks outside the home environment. Neonatal dopamine terminal damage leads to a lifelong hyperreactivity to novel objects and experiences in an unfamiliar environment, but normal responses to the same stimuli in the home cage. Again, this pattern of behavior is observed in the rat model of developmental iron deficiency. ${ }^{63}$ Neonatal dopaminergic or cortical injury also leads to chronic vulnerability to distraction, particularly in an unfamiliar situation. ${ }^{88,91,92}$ Thus, early alterations in dopamine and associated pathways have long-term effects on context-dependent attentional and affective responses.

Specific perinatal damage to nigrostriatal dopamine neurons or intrinsic striatal or corticostriatal neurons, whether induced by early iron deficiency or pharmacologic injury, results in fine motor, gross motor, motor sequencing, and sensory deficits in rats. ${ }^{63,86,88,93-96}$ These data further support the hypothesis that iron deficiency in infancy leads to a chronic disorder of dopaminergic and corticostriatal function. Moreover, it is possible that, despite iron repletion, the brains of affected animals would be more chronically vulnerable to subsequent insults, such as stress or age-associated forebrain degenerative events. ${ }^{88}$

\section{RELATING BASIC SCIENCE FINDINGS TO LONG-TERM EFFECTS IN THE HUMAN}

In the available long-term follow-up studies of iron deficiency in the human infant, the findings that seem most tightly linked to alterations in myelination are slower conduction in the auditory and visual systems. ${ }^{59}$ Both of these sensory systems are rapidly myelinating during the period of iron deficiency, and they are critical for learning and social interaction. The loss of myelin compaction could directly contribute to long-lasting, slower conduction for auditory potentials and VEPs. It is also likely that there are other intracerebral effects, given that so many brain systems are myelinating during this period. Thus, impaired myelination could underlie other poorer outcomes.

The findings of poorer recognition memory in infants at high risk for iron deficiency (due to maternal diabetes) appear to fit with an effect of iron deficiency on the hippocampus and related components of the central nervous system. ${ }^{38}$ With regard to alterations in neurotransmitter functioning, some of the social/emotional and neurocognitive findings appear to make sense in terms of effects of early iron deficiency on the dopamine system and the hippocampus. Dopamine plays a major role in the systems of behavioral activation and inhibition and the degree to which individuals experience inherent reward. The affective changes in iron-deficient anemic infants (wariness, hesitance, absence of positive affect), their lack of social referencing, and the observation that toys can be taken away from them without protest all 
seem to make sense in this context. In addition, differences between home and laboratory in spontaneous motor activity suggest that the iron-deficient anemic children respond differently to context-with a reduction in motor activity after the stress or unfamiliarity of the laboratory.

It is therefore plausible that iron deficiency, through reduced energy, impaired glial function, altered activation of monoamine circuits, etc., alters experience-dependent processes such as dendritic arborization that are critical to brain structure and function during early development. ${ }^{69,94}$ While iron deficient, the developmental trajectory may be put "on hold" or progress more slowly or out of synchrony, causing a delay or disruption in brain development. As long as the processes remain capable of plasticity, recovery post iron deficiency remains more or less possible. Ultimately, however, the developmental windows of opportunity end, and if potential metabolic reprogramming of genes induced by iron deficiency is not relieved, those programs potentially become more permanent.

Altered behavior and development in infancy can also result in altered interactions with the care-giving environment. In the human infant with chronic, severe iron deficiency, delayed or mistimed sensory input, together with cognitive, motor, and affective changes, may adversely affect the infant's interactions with the physical and social environment, thereby compromising development even further. ${ }^{97-99}$ If an iron-deficient infant is unable to elicit or benefit from nurturant interactions from a caregiver, the child may have fewer enriching experiences that foster optimal development. Over time, direct effects of iron deficiency on the developing brain and indirect effects via limited environmental input may, in combination, contribute to poorer long-term behavioral and developmental outcome. ${ }^{13}$

\section{ACKNOWLEDGEMENTS}

Dr. Lozoff received, as principal investigator, a program project grant from the US National Institutes of Health (P01 HD39386, Brain and Behavior in Early Iron Deficiency). The entire group of investigators participating in the Brain and Behavior in Early Iron Deficiency Program Project, which contributed to our thinking about long-term effects.

\section{REFERENCES}

1. Beard J, Stoltzfus R. Iron-deficiency anemia: reexamining the nature and magnitude of the public health problem. J Nutr. 2001;131:563S-703S.

2. Leung AKC, Chan KW. Iron deficiency anemia. Adv Pediatr. 2001;48:385-408.

3. Beard JL, Connor JR. Iron status and neural functioning. Ann Rev Nutr. 2003;23:41-58.
4. Grantham-McGregor S, Ani C. A review of studies on the effect of iron deficiency on cognitive development in children. J Nutr. 2001;131:649S-668S.

5. Black MM, Baqui $\mathrm{AH}$, Zaman K, et al. Iron and zinc supplementation promote motor development and exploratory behavior among Bangladeshi infants. Am J Clin Nutr. 2004;80:903-910.

6. Pollitt E, Schurch B. Developmental pathways of the malnourished child: results of a supplementation trial in Indonesia. Eur J Clin Nutr. 2000;54:S1-S114.

7. Stoltzfus RJ, Kvalsvig JD, Chwaya HM, et al. Effects of iron supplementation and anthelmintic treatment on motor and language development of preschool children in Zanzibar: double blind, placebo controlled study. BMJ. 2001;323:1389-1393.

8. Heywood A, Oppenheimer S, Heywood P, et al. Behavioral effects of iron supplementation in infants in Madang, Papua New Guinea. Am J Clin Nutr. 1989;50:630-640.

9. Lind $\mathrm{T}$, Lonnerdal $\mathrm{B}$, Stenlund $\mathrm{H}$, et al. A communitybased randomized controlled trial of iron and zinc supplementation in Indonesian infants: effects on growth and development. Am J Clin Nutr. 2004;80: 729-736.

10. Siegel EH, Stoltzfus RJ, Kariger PK, et al. Growth indices, anemia, and diet independently predict motor milestone acquisition of infants in south central Nepal. J Nutr. 2005;135:2840-2844.

11. Kariger PK, Stoltzfus RJ, Olney D, et al. Iron deficiency and physical growth predict attainment of walking but not crawling in poorly nourished Zanzibari infants. J Nutr. 2005;135:814-819.

12. Black MM, Sazawal S, Black RE, et al. Micronutrient supplementation leads to improved development and behavior among infants born small-for-gestational age. Pediatr Res. 2002;51:2565.

13. Lozoff B, Black M. Impact of micronutrient deficiencies on behavior and development. In: Pettifor J, Zlotkin SH, eds. Nutrition-Micronutrient Deficiencies during the Weaning Period and the First Years of Life. 2003; Basel: Karger; 119-135.

14. Sachdev H, Gera T, Nestel P. Effect of iron supplementation on mental and motor development in children: systematic review of randomised controlled trials. Pub Health Nutr. 2005;8:117-132.

15. Lozoff B, De Andraca I, Castillo M, et al. Behavioral and developmental effects of preventing iron-deficiency anemia in healthy full-term infants. Pediatrics. 2003;112:846-854.

16. Shafir Liberzon T, Angulo-Barroso R, Calatroni A, et al. Iron deficiency affects motor development in 9-month-old infants. Pediatr Res. 2005;57:1731.

17. Sherriff A, Emond A, Bell JC, et al. Should infants be screened for anaemia? A prospective study investigating the relation between haemoglobin at 8,12 , and 18 months and development at 18 months. Arch Dis Child. 2001;84:480-485.

18. Moffatt MEK, Longstaffe S, Besant J, et al. Prevention of iron deficiency and psychomotor decline in high risk infants through iron fortified infant formula: A randomized clinical trial. J Pediatr. 1994;125:527534.

19. Friel JK, Aziz K, Andrews WL, et al. A doublemasked, randomized control trial of iron supple- 
mentation in early infancy in healthy full-term breast-fed infants. J Pediatr. 2003;143:582-586.

20. Williams J, Wolff A, Daly A, et al. Iron supplemented formula milk related to reduction in psychomotor decline in infants for inner city areas: randomised study. BMJ. 1999;318:693-698.

21. Roncagliolo M, Garrido M, Walter T, et al. Evidence of altered central nervous system development in infants with iron deficiency anemia at 6 mo: Delayed maturation of auditory brain stem responses. Am J Clin Nutr. 1998;68:683-690.

22. Li YY, Wang HM, Wang WG. The effect of iron deficiency anemia on the auditory brainstem response in infant. Natl Med J China. 1994;74:367369.

23. Algarin C, Peirano P, Garrido M, et al. Iron deficient anemic infants have decreased rapid eye movements density in active sleep [abstract]. Sleep. 2003;(suppl):A146.

24. Burden MJ, Armony-Sivan R, Westerlund A, et al. Preliminary Findings from an ERP Study of Memory Processing in Iron Deficient Infants. Presented at the International Conference on Information Systems; December 12-15, 2004; Washington, DC.

25. Abrams JM, Jacobson SW, Lozoff B, et al. EEG correlates of iron deficiency in infancy. Pediatr Res. 2005;57:1287.

26. Sarici SU, Serdar MA, Dundaroz MR, et al. Brainstem auditory-evoked potentials in iron-deficiency anemia. Pediatr Neurol. 2001;24:205-208.

27. Angulo-Kinzler RM, Peirano P, Lin E, et al. Spontaneous motor activity in human infants with iron deficiency anemia. Early Hum Dev. 2002;66:67-79.

28. Angulo-Kinzler RM, Peirano P, Lin E, et al. Twentyfour hour motor activity in human infants with and without iron-deficiency anemia. Early Hum Dev. 2002;70:85-101.

29. Idjradinata P, Pollitt E. Reversal of developmental delays in iron-deficient anaemic infants treated with iron. Lancet. 1993;341:1-4.

30. Akman M, Cebeci D, Okur V, et al. The effects of iron deficiency on infants' developmental test performance. Acta Paediatr. 2004;93:1391-1396.

31. Antunes H. Iron Deficiency Anaemia in Infants - A Prospective Neurodevelopment Evaluation. University of Portugal; 2004.

32. Allen LH. Anemia and iron deficiency: effects on pregnancy outcome. Am J Clin Nutr. 2000;71: 1280S-1284S.

33. Vaughn J, Brown J, Carter JP. The effects of maternal anemia on infant behavior. J Natl Med Assoc. 1986;78:963-968.

34. Wachs TD, Pollitt E, Cuerto S, et al. Relation of neonatal iron status to individual variability in neonatal temperament. Dev Psychobiol. 2005;46:141153.

35. Rao R, Georgieff MK. Perinatal aspects of iron metabolism. Acta Paediatr Suppl. 2002;91:124-129.

36. Armony-Sivan R, Eidelman Al, Lanir A, et al. Iron status and neurobehavioral development of premature infants. J Perinatol. 2004;24:757-762.

37. Nelson CA, Wewerka SS, Borscheid AJ, et al. Electrophysiologic evidence of impaired cross-modal recognition memory in 8 -month-old infants of diabetic mothers. J Pediatr. 2003;142:575-582.
38. Nelson CA, Wewerka S, Thomas KM, et al. Neurocognitive sequelae of infants of diabetic mothers. Behav Neurosci. 2000;114:950-956.

39. DeBoer T, Wewerka S, Bauer PJ, et al. Explicit memory performance in infants of diabetic mothers at 1 year of age. Dev Med Child Neurol. 2005;47: 525-531.

40. Siddappa AM, Georgieff MK, Wewerka S, et al. Iron deficiency alters auditory recognition memory in newborn infants of diabetic mothers. Pediatr Res. 2004;55:1034-1041.

41. Lozoff B. Has iron deficiency been shown to cause altered behavior in infants? In: Dobbing J, ed. Brain, Behaviour, and Iron in Infant Diet. New York: Springer-Verlag; 1990; 107-131.

42. Palti H, Pevsner B, Adler B. Does anemia in infancy affect achievement on developmental and intelligence tests? Hum Biol. 1983;55:189-194.

43. Dommergues JP, Archambeaud B, Ducot $\mathrm{Y}$, et al. Iron deficiency and psychomotor development scores: A longitudinal study between ages 10 months and 4 years. Arch Fr Pediatr. 1989;46:487490.

44. Wasserman G, Graziano JH, Factor-Litvak P, et al. Independent effects of lead exposure and iron deficiency anemia on developmental outcome at age 2 years. J Pediatr. 1992;121:695-703.

45. Wasserman GA, Graziano JH, Factor-Litvak P, et al. Consequences of lead exposure and iron supplementation on childhood development at age 4 years. Neurotoxicol Teratol. 1994;16:233-240.

46. Lozoff B, Jimenez E, Wolf AW. Long-term developmental outcome of infants with iron deficiency. N Engl J Med. 1991;325:687-694.

47. Corapci F, Radan AE, Lozoff B. Iron deficiency in infancy and mother-child interaction at 5 years. J Behav Dev Pediatr. 2006; In press.

48. De Andraca I, Walter T, Castillo M, et al. Iron Deficiency Anemia and Its Effects upon Psychological Development at Preschool Age: A Longitudinal Study. Nestlé Foundation Nutrition Annual Report (1990). Vevey, Switzerland: Nestec Ltd; 1991; 5362.

49. Tamura T, Goldenberg RL, Hou J, et al. Cord serum ferritin concentrations and mental and psychomotor development of children at five years of age. J Pediatr. 2002;140:165-170.

50. Cantwell RJ. The long term neurological sequelae of anemia in infancy. Pediatr Res. 1974;342:68.

51. Palti H, Meijer A, Adler B. Learning achievement and behavior at school of anemic and non-anemic infants. Early Hum Dev. 1985;10:217-223.

52. Hurtado EK, Claussen AH, Scott KG. Early childhood anemia and mild or moderate mental retardation. Am J Clin Nutr. 1999;69:115-119.

53. Lozoff B, Jimenez E, Hagen J, et al. Poorer behavioral and developmental outcome more than 10 years after treatment for iron deficiency in infancy. Pediatrics. 2000;105:E51.

54. Shafir T, Angulo-Barroso R, Calatroni A, et al. Effects of iron deficiency on patterns of motor development over time. Submitted manuscript

55. Lozoff B, Smith J, Liberzon T, et al. Longitudinal analysis of cognitive and motor effects of iron defi- 
ciency in infancy. APA Plenary Presentation. Pediatr Res. 2004;55:23A.

56. Lozoff B, Jimenez E, Walter T. Double burden of iron deficiency and low socio-economic status: a growth curve analysis of cognitive test scores to 19 years. Arch Pediatr Adolesc Med. 2006; In press.

57. Peirano $P$, Algarin C, Garrido $M$, et al. Cerebral executive function in preadolescents is affected by iron deficiency in infancy. Pediatr Res. 2004;55: 279A.

58. Burden M, Koss M, Lozoff B. Neurocognitive differences in 19-year-olds treated for iron deficiency in infancy. Pediatr Res. 2004;55:279A.

59. Algarin C, Peirano P, Garrido M, et al. Iron deficiency anemia in infancy: Long-lasting effects on auditory and visual systems functioning. Pediatr Res. 2003;53:217-223.

60. Peirano P, Algarin C, Garrido M, et al. Iron deficiency anemia (IDA) in infancy is associated with altered sleep states organization in early childhood. Submitted manuscript

61. Angulo-Barroso RM, Peirano P, Calatroni A, et al. Forty-eight-hour motor activity in 4-year-old children who had iron-deficiency anemia in infancy. Submitted manuscript

62. Beard JL, Felt B, Schallert T, Burhans M, Connor JR, Georgieff MK. Moderate iron deficiency in infancy: Biology and behavior in young rats. Behav Brain Res. 2006; Epub ahead of print.

63. Felt BT, Beard JL, Schallert $\mathrm{T}$, et al. Persistent neurochemical and behavioral abnormalities in adulthood despite early iron supplementation for perinatal iron deficiency anemia in rats. Brain Behav Res. 2006; In press.

64. Clardy SL, Wang X, Zhao W, et al. Acute and chronic effects of developmental iron deficiency on mRNA expression patterns in the brain. J Neural Transm. 2006; In press.

65. Thompson RA, Nelson CA. Developmental science and the media. Early brain development. Am Psychol. 2001;56:5-15.

66. Kretchmer N, Beard JL, Carlson S. The role of nutrition in the development of normal cognition. Am J Clin Nutr. 1996;63:997S-1001S.

67. DeUngria M, Rao R, Wobken JD, et al. Perinatal iron deficiency decreases cytochrome c oxidase (CytOx) activity in selected regions of neonatal rat brain. Pediatr Res. 2000;48:169-176.

68. Rao R, Tkac I, Townsend EL, et al. Perinatal iron deficiency alters the neurochemical profile of the developing rat hippocampus. J Nutr. 2003;133: 3215-3221.

69. Jorgenson LA, Wobken JD, Georgieff MK. Perinatal iron deficiency alters apical dendritic growth in hippocampal CA1 pyramidal neurons. Dev Neurosci. 2003;25:412-420.

70. Yoo YE, Hong JH, Hur KC, et al. Iron enhances NGF-induced neurite outgrowth in PC12 cells. Mol Cells. 2004;17:340-346.

71. Yu GS, Steinkirchner TM, Rao GA, et al. Effect of prenatal iron deficiency on myelination in rat pups. Am J Pathol. 1986;125:620-624.

72. Oloyede OB, Folayan AT, Odutuga AA. Effects of low-iron status and deficiency of essential fatty ac- ids on some biochemical constituents of rat brain. Biochem Int. 1992;27:913-922.

73. Larkin EC, Rao GA. Importance of fetal and neonatal iron: Adequacy for normal development of central nervous system. In: Dobbing J, ed. Brain, Behaviour, and Iron in the Infant Diet. London: Springer-Verlag; 1990; 43-62.

74. Kwik-Uribe CL, Gietzen D, German JB, et al. Chronic marginal iron intakes during early development in mice result in persistent changes in dopamine metabolism and myelin composition. J Nutr. 2000;130:2821-2830.

75. Beard JL, Wiesinger JA, Connor JR. Pre- and postweaning iron deficiency alters myelination in Sprague-Dawley rats. Dev Neurosci. 2003;25:308315.

76. Ortiz E, Pasquini JM, Thompson K, et al. Effect of manipulation of iron storage, transport, or availability on myelin composition and brain iron content in three different animal models. J Neurosci Res. 2004;77:681-689.

77. Morath DJ, Mayer-Proschel M. Iron deficiency during embryogenesis and consequences for oligodendrocyte generation in vivo. Dev Neurosci. 2002;24: 197-207.

78. Connor JR, Phillips TM, Lakshman MR, et al. Regional variation in the levels of transferrin in the CNS of normal and myelin-deficient rats. J Neurochem. 1987;49:1523-1529.

79. Han J, Day JR, Connor JR, et al. Gene expression of transferrin and transferrin receptor in brains of control vs. iron-deficient rats. Nutr Neurosci. 2003;6:110.

80. Wigglesworth JM, Baum H. Iron dependent enzymes in the brain. In: Youdim MBH, ed. Brain Iron: Neurochemical and Behavioural Aspects. New York: Taylor and Francis; 1988; 25-66.

81. Morse A, Beard JL, Jones B. Behavioral and neurochemical alterations in iron deficient mice. Proc Soc Exp Biol Med. 1999;220:147-152.

82. Burhans MS, Dailey C, Beard Z, et al. Iron deficiency: differential effects on monoamine transporters. Nutr Neurosci. 2005;8:31-38.

83. Buwen J. hDAT Metabolism in Iron-Deficient Neuroblastoma Cells [dissertation]. University Park, PA: The Pennsylvania State University; 2005.

84. Ye Z, Connor JR. Identification of iron responsive genes by screening cDNA libraries from suppression subtractive hybridization with antisense probes from three iron conditions. Nucleic Acids Res. 2000; 28:1802-1807.

85. Wang X, Wiesinger J, Beard J, et al. Thy1 expression in the brain is affected by iron and is decreased in Restless Legs Syndrome. J Neurol Sci. 2004;220: 59-66.

86. Whishaw IQ, Funk DR, Hawryluk SJ, et al. Absence of sparing of spatial navigation, skilled forelimb and tongue use and limb posture in the rat after neonatal dopamine depletion. Physiol Behav. 1987;40:247253.

87. Feeser HR, Raskin LA. Effects of neonatal dopamine depletion on spatial ability during ontogeny. Behav Neurosci. 1987;101:812-818.

88. Schallert T, Petrie BF, Whishaw IQ. Neonatal dopamine depletion: Spared and unspared sensorimotor 
and attentional disorders and effects of further depletion in adulthood. Psychobiology. 1989;17:386396.

89. Day LB, Weisend M, Sutherland RJ, et al. The hippocampus is not necessary for a place response but may be necessary for pliancy. Behav Neurosci. 1999;113:914-924.

90. Beard JL, Dawson H, Pinero DJ. Iron metabolism: a comprehensive review. Nutr Rev. 1996;54:295-317.

91. Schallert T, Whishaw IQ. Bilateral cutaneous stimulation of the somatosensory system in hemidecorticate rats. Behav Neurosci. 1984;98:518-540.

92. Schallert T. Neonatal hemidecortication and bilateral cutaneous stimulation in rats. Dev Psychobiol. 1985;18:501-514.

93. Felt BT, Schallert T, Shao J, et al. Early appearance of functional deficits after neonatal excitotoxic and hypoxic-ischemic injury: fragile recovery after development and role of the NMDA receptor. Dev Neurosci. 2002;24:418-425.

94. Kolb B. Neurological models. In: Whishaw IQ, Kolb $\mathrm{B}$, eds. The Behavior of the Laboratory Rat. New York: Oxford University Press; 2005; 449-461.
95. Kolb B, Gibb R, Gonzales C. Cortical injury and neuroplasticity during brain development. In: Shaw CA, McEachern JC, eds. Toward a Theory of Neuroplasticity. New York: Elsevier; 2001; 223-243.

96. Barks JD, Li XL, Pecina S, et al. Delayed appearance of functional deficits after neonatal hypoxicischemic and excitotoxic brain injury, and recovery during later development. Pediatr Res. 2002;51: 2653.

97. Black JE, Jones TA, Nelson CA, et al. Neural plasticity and developing brain. In: Alessi NE, Coyle JT, Harrison SI, et al., eds. The Handbook of Child and Adolescent Psychiatry. New York: John Wiley \& Sons; 1998; 31-53.

98. Greenough WT, Black JE. Induction of brain structure by experience: Substrates for cognitive development. In: Gunnar M, Nelson C, eds. Developmental Behavioral Neuroscience. The Minnesota Symposia on Child Psychology. Vol. 24. Hillsdale, NJ: Lawrence Erlbaum; 1992; 155-200.

99. Kleim JA, Jones TA, Schallert T. Motor enrichment and the induction of plasticity before or after brain injury. Neurochem Res. 2003;28:1757-1769. 